\title{
DESIGN THINKING NA EAD: EXPERIÊNCIAS NO CST EM GESTÃO COMERCIAL
}

\author{
CURITIBA/PR MAIO/2018
}

\author{
Andréa Barbosa Delfini Paulo - UniOpet - deabarbs@gmail.com \\ Fernanda Rodrigues Pucci - UniOpet - fernanda.r.pucci@gmail.com \\ Mara Rúbia Muniz Monteiro－UniOpet - monteiro.mrm@gmail.com
}

Tipo: Relato de Experiência Inovadora (EI)

Categoria: Métodos e Tecnologias

Setor Educacional: EDUCAÇÃO SUPERIOR

\begin{abstract}
RESUMO
Este estudo apesenta o desenvolvimento de um trabalho realizado no Curso Superior Tecnologia em Gestão Comercial das Faculdades Opet, na modalidade EAD. Trata-se da aplicação de projetos por equipes com o propósito de desenvolvimento de um modelo de negócio inovador construído a partir da metodologia do Design Thinking e BMG canvas. O objetivo principal do projeto é promover a integração entre a teoria e a prática dos conteúdos apresentados aos alunos. Implementado em 2014, e com ciclos de dois anos, tempo de duração do curso, o trabalho é aplicado por etapas e avança a cada período. Envolve estudantes, professores, comunidade e profissionais do mercado. Consta, atualmente, com cerca de 32 projetos com características de inovação, mas principalmente, com construção de conhecimento e aplicação efetiva, pois muitos se tornaram empresas dos próprios estudantes. Trata-se de um trabalho periódico, que traz resultados a cada seis meses, o qual colabora com a evolução do potencial dos alunos no decorrer do curso, sendo a sua metodologia aplicada por etapas, envolvendo as disciplinas do semestre aplicadas no projeto, construído colaborativamente pelos alunos do curso.
\end{abstract}

Palavras-chave: EaD. Design Thinking. Canvas. Aprendizagem inovadora. 


\section{Introdução}

A Faculdades Opet é a primeira instituição particular do sul do Brasil a ofertar cursos na modalidade de tecnologia, e desde 2002 oferece também cursos de Especialização e MBA. Neste contexto de inovação e protagonismo, a educação a distância Opet vem ganhando credibilidade conforme implementa novos projetos de metodologias ativas. Sendo, pois, este o cenário que marca o presente Relato de Experiência Inovador, o qual está baseado em um trabalho desenvolvido no CST em Gestão Comercial das Faculdades Opet, na modalidade EAD, com uma proposta construída a partir da metodologia do Design Thinking e BMG canvas a partir da realização de projetos por equipes, com o propósito de desenvolvimento de um modelo de negócio inovador.

Em consonância com os objetivos e educacionais e proposição da IES - quanto à inovação, pioneirismo e transformação pela educação - foi desenvolvido o projeto de Design Thinking (DT) para a principal atividade de integração de conteúdos do curso de Gestão Comercial, o TCC, em um projeto de empreendedorismo.

Os principais objetivos de uso desse método são: integrar teorias e práticas; estimular a capacidade de inovar e empreender no aluno, vivenciando conceitos de modo autônomo na criação de um produto/serviço. As ações são direcionadas por técnicas que abarcam o mercado de trabalho e os conceitos estudados.

O desafio fundamental é fazer com que o aluno seja o protagonista das atividades e do seu método de aprender; onde o professor é um mediador e não um apresentador de conteúdos, alterando as práticas pedagógicas tradicionais.

\section{Contextualização da proposta de Design Thinking na EAD}

O Grupo Opet foi fundado em 25 de janeiro de 1973, ofertando cursos profissionalizantes. Pioneiro na oferta de cursos de informática, formando mais de 100 mil profissionais. Atualmente é composto pela Editora Opet, que além da gráfica, possui o Centro de pesquisa e desenvolvimento pedagógico que produz e distribui o sistema de ensino Opet.

O Grupo possui também uma cidade Mirim, onde é praticada a cidadania e os valores sociais, projeto referência nacional na educação infantil e ensino fundamental, que passou a ser utilizada nos cursos de graduação de Pedagogia, Direito, Gestão Comercial, Processos Gerenciais, entre outros. 
Em 2010, a Educação a Distância tem início com os cursos de Gestão Comercial e Pedagogia. Nesse percurso, ganhou destaque as Faculdades Opet com a utilização de novas tecnologias de ensino-aprendizagem e da gestão educação. De tal modo que passou a integrar, em 2014, o consórcio STHEM Brasil Laspau, dando início à implantação de metodologias ativas de aprendizagem.

Foi nesse cenário que a IES propôs o projeto de Design Thinking (DT), em uma perspectiva inovadora e empreendedora.

O DT é uma técnica que facilita o raciocínio criativo e não linear (BROWN, 2010). Foi incorporado por empreendedores no desenvolvimento rápido da inovação em negócios e produtos. Em síntese, "o design thinking é um processo para a resolução de problemas complexos, desenvolvido colaborativamente [...]" (MARTINS FILHO et al, 2015, p.587).

Quanto ao Business Model Canvas, foi proposto por Alexander Osterwalder (2004). Trata-se de uma ferramenta que auxilia desenvolvimento de modelos de negócio (OSTERWALDER; PIGNEUR, 2004).

O DT e o canvas têm sido utilizados no campo educacional como mediador dos processos de ensino e aprendizagem.

Na proposta do projeto construído pela IES, o método engloba o DT e o Canvas BMG (OSTERWALDER, 2004), a observação de cenários, necessidades dos clientes, e projeção de modelos inovadores, com estratégias viáveis de negócios e criação facilitada de oportunidades no CST em Gestão Comercial.

\section{Procedimentos metodológicos}

O projeto elaborado pelas Faculdades Opet com base na metodologia do Design Thinking e BMG canvas, foi desenvolvido no Curso Superior Tecnologia em Gestão Comercial, na modalidade EAD, sendo implementado em 2014, e com ciclos de dois anos. Já participaram cerca de 200 estudantes a cada ciclo, 19 professores e profissionais do mercado, além de duas professoras responsáveis pelo projeto. Incluiu cerca de 32 projetos.

Trata-se de um trabalho periódico, que traz resultados a cada seis meses. É aplicado por etapas e envolve as disciplinas do semestre, sendo construído colaborativamente pelos alunos do curso. 


\section{Apresentação do projeto}

O projeto envolve todos os períodos do curso de Gestão Comercial. Até o momento, já capacitou 12 professores, para as orientações quanto a cada conteúdo aplicado nos projetos; e mais 5 tutores, para direcionar e mediar as atividades nos encontros presencias (a cada 15 dias). Além disso, envolveu em torno de 200 alunos a cada ciclo desde o primeiro semestre do curso até 2017 (figura 1).

Figura 1: Desenvolvimento do projeto.

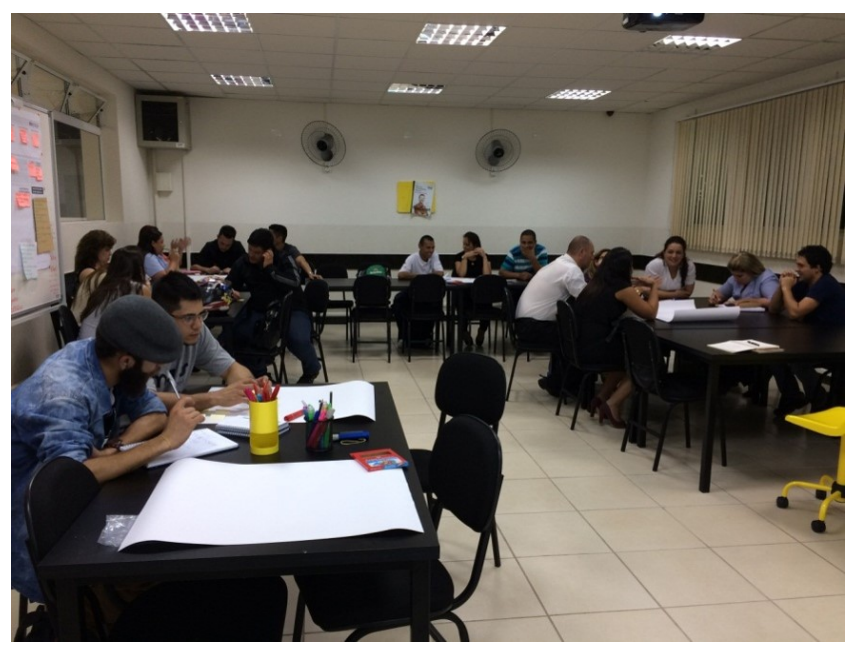

Fonte: Arquivo do curso 2017.

Nota: Turma de alunos do primeiro período desenvolvendo seus projetos.

Desde o primeiro semestre os alunos desenvolvem projetos de DT com o propósito de criar um produto sustentável e inovador. Nessa etapa, aplicam-se as disciplinas de fundamentos de gestão para delinear a proposta, gestão de marketing para estruturar estratégias de mercado, sistemas de informação para levantamento de oportunidade e análise do mercado potencial e gestão de pessoas para a organização da proposta.

Na segunda etapa e período do curso, os alunos devem desenvolver seu segmento de mercado, e utilizam das disciplinas de pesquisa, marketing de serviços, comportamento do consumidor e logística. O momento é delinear um mapa de empatia (ou Persona) e fazer a compreensão do segmento escolhido (figura 2). 
Figura 2: Mapa da empatia.

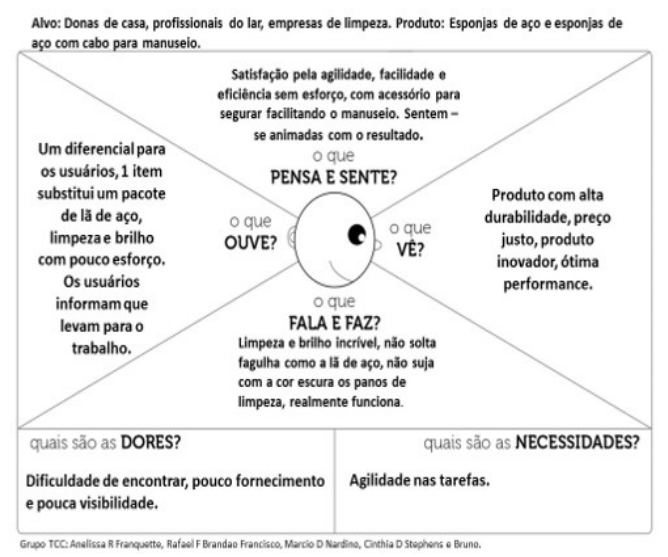

Fonte: arquivo do curso 2017.

Nota: Persona de um projeto construído pelos alunos.

$\mathrm{Na}$ terceira etapa acontece o desenvolvimento da proposta em si, ela deve atender as necessidades levantadas. Os alunos utilizam das disciplinas de metodologia e planejamento e "casam" as informações no mapa Proposta de Valor, e levam em consideração tudo que foi estudado.

$\mathrm{Na}$ etapa final, os alunos desenvolvem um modelo de negócios com base no Canvas BMG. Nesse momento, são testados todos os conhecimentos desenvolvidos. Marketing de relacionamento, gestão de marketing, de vendas, planejamento estratégico entre outras exigidas para o preenchimento do mapa canvas (figura 3 ).

Figura 3: Mapa Canvas BMG exemplo.

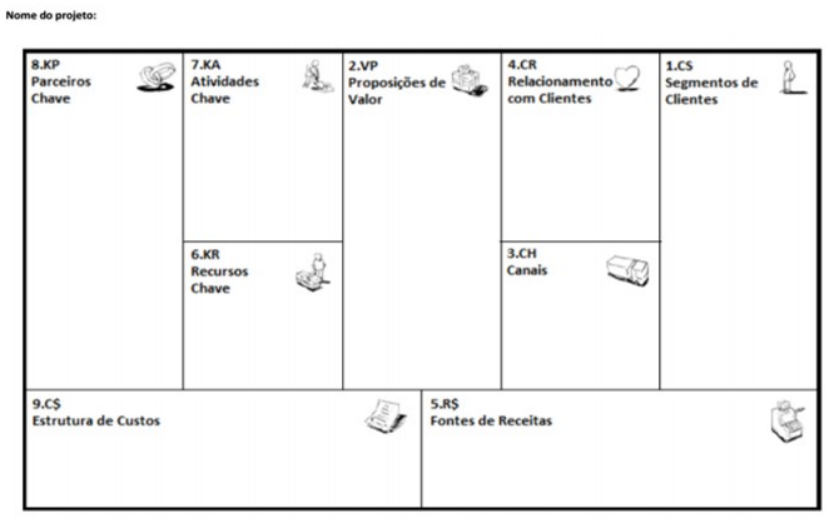

Fonte: SHERER, 2014. 
Nota: o mapa canvas apresenta uma estrutura a ser preenchida que facilita a visualização de situações específicas.

Um dos trabalhos desenvolvidos em 2016 foi o de um caminhão Baú com capacidade de se adaptar à diferentes alturas de produtos e ambientes de abastecimento. O Canvas BMG foi completado com todas as informações de nichos e de conteúdos contemplados em cada matéria (figura 4).

Figura 4: Canvas Caminhão Baú.

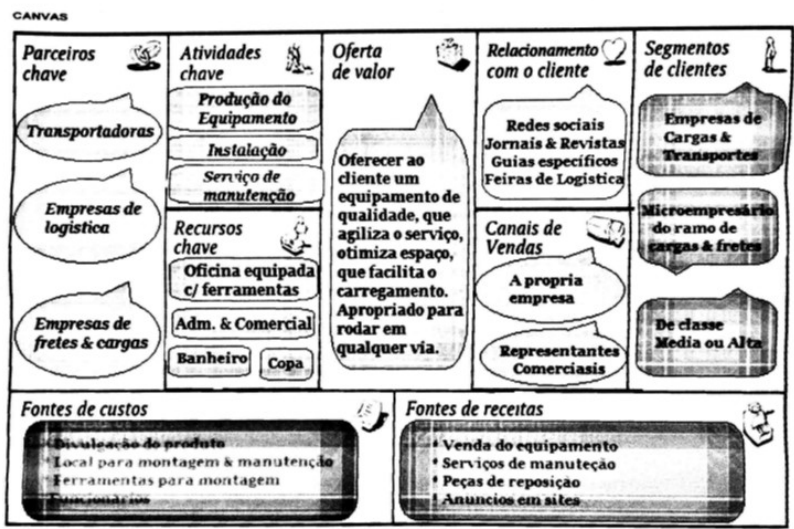

Fonte: Arquivo do curso 2016.

Nota: Caminhão Baú descrito com o Canvas BMG.

Além do Canvas BMG, apresentado o desenvolvimento, passou-se da ideação para a prototipação (figura 5).

Figura 5: Prototipação.

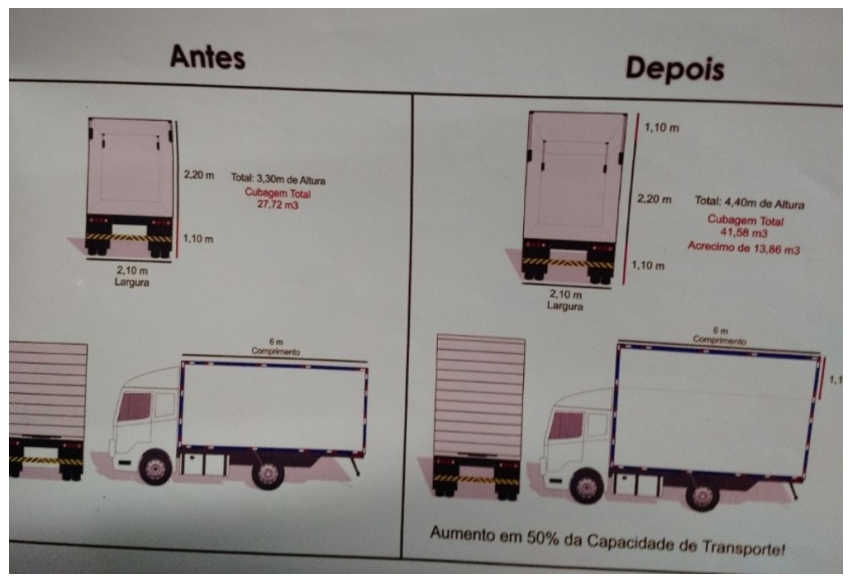

Fonte: Arquivo do curso 2016. 
Nota: Protótipo desenvolvido para apresentar a ideia.

Cada uma das etapas é mediada pelos tutores presenciais, as dúvidas com relação ao processo e o método de desenvolvimento das propostas são sanadas pelos próprios mediadores. A proposta completa é apresentada para o corpo docente do curso e para empresários de Curitiba, numa feira de novos negócios. As equipes defendem suas estratégias em um tempo reduzido e conversam com profissionais do mercado recebendo seu feedback em relação à proposta.

Para que o projeto aconteça ao longo dos períodos os alunos precisam ter passado por cada uma das disciplinas, mas como um dos objetivos é gerar autonomia de estudo, o processo pode ser aplicado e desenvolvido por alunos em qualquer etapa do curso, o que caracteriza a gestão participativa do projeto. Os alunos são os decisores dos critérios necessários e desenvolvem seus próprios percursos para ir de encontro a esse conhecimento.

\section{Discussão dos resultados}

Como a implantação dessa metodologia tem o objetivo de promover a integração dos conceitos teóricos com a prática, e assim, desenvolver a capacidade de inovar do discente, aprimorando seu talento empreendedor e provocando a tomada de decisão, os resultados estão relacionados a estes objetivos.

Por se tratar de um projeto periódico com ciclos de quatro períodos, pode ser avaliado com frequência e a cada conclusão de curso por uma turma de estudantes. Esta facilidade permite comparar a produtividade acadêmica dos alunos e o uso completo dos conhecimentos adquiridos. Assim, é possível atualizar a proposta, e implementar alterações e inovações a cada semestre conforme os feedbacks dos protagonistas que são os acadêmicos, e dos profissionais do mercado com suas impressões sobre a produção e, também dos professores, com as avaliações sob critérios prévios comparados.

Cada etapa realizada no método do DT requer que o aluno revise os conteúdos de períodos já cursados, para que ele tenha uma densa visão tanto do produto/serviço que está sendo elaborado quanto do mercado, o que refletiu em conquista total dos alunos, pois preferem o trabalho prático ao teórico (artigo científico), e recebem formação mais ativa e empreendedora com produtos e serviços sustentáveis.

Houve, ainda, intensa integração entre os estudantes, promovendo seu network antes 
de sair da Faculdade, com a realização de contatos com os profissionais avaliadores e observadores das propostas apresentadas no projeto e, assim maior integração com o mercado.

Também é importante destacar outro resultado relevante. Com dados de pesquisa de CPA os alunos apontaram a aprovação do método em 35\% de uma turma para outra, e observou-se também melhoria significativa nos índices oficiais como a prova do ENADE. Onde houve a melhoria de 15\% nas questões específicas e gerais de 2015 em comparação com a edição anterior.

Além disso, comparando os índices anteriores de aplicação do projeto, os resultados vêm sendo bastante inspiradores. O primeiro indicador é o de participação dos acadêmicos nos encontros presenciais, que não são obrigatórios, onde ocorreu uma ampliação de $10 \%$ no $3^{\circ}$ período e $70 \%$ no $4^{\text {a }}$ período; um aumento total de $35 \%$ do primeiro para o último período do curso. E um aumento de 10\% de uma turma concluinte para outra. Ou seja, não apenas os encontros foram mais proveitosos e participativos, como a empolgação com a produtividade foi repassada para as turmas seguintes com a apresentação dos projetos.

\section{Considerações finais}

Com o projeto proposto pelas Faculdades Opet, baseado na metodologia do Design Thinking e BMG canvas, o curso de Gestão Comercial objetivou romper coma forma tradicional de ensino/aprendizagem produzida anteriormente por meio dos artigos ou monografias escritas no Trabalho de Conclusão de Curso. O projeto pretende promover a gestão participativa dos estudantes na definição de seus próprios percursos e critérios no processo de ensino/aprendizagem, com a autonomia completa do aluno, mediado por tutores.

O método aplicado intenciona promover a experiência do aluno junto aos seus métodos de estudo, modificando não só o desenvolvimento do conhecimento como a forma de avaliação e os critérios adotados.

As atividades e projetos surgiram no intuito de promover o aprendizado protagonizado pelo aluno com os docentes apenas mediando. Os projetos promovem o aprendizado colaborativo, o desenvolvimento de habilidades de trabalho em equipes e a integração com a prática. Além disso, a interdisciplinaridade promovida nas atividades é fundamental para que os alunos desenvolvam cada uma das etapas, onde os conteúdos das disciplinas são aplicados. 
Este projeto destaca-se em relevância, pois prepara o estudante para atuar no mercado, lidando com informações verdadeiras, em que eles podem estender para um projeto pessoal, inserindo-se no mercado de trabalho como autônomo ou como intraempreendedor. Muitos dos empresários participantes acreditam nos potenciais dos projetos, indicando financiadores, ou contatos.

\section{Referências}

BROWN, Tim. Design Thinking: uma poderosa metodologia para decretar o fim das velhas ideias. Rio de Janeiro: Elsevier, 2010.

MARTINS FILHO, Vilson et al. Design thinking, cognição e educação no século XXI. Revista Diálogo Educacional, v.15, p.580-596, mai./ago. 2015. Disponível em: Acesso em: 09 mai. 2018.

OSTERWALDER, Alexander. The Business Model Ontology: a proposition in a Design Science Approach. PhD Thesis, University of Lausanne, Switzerland, 2004.

OSTERWALDER, Alexander; PIGNEUR, Yves. Business Model Generation - Inovação em Modelos de Negócios: um manual para visionários, inovadores e revolucionários. Rio de Janeiro, RJ: Alta Books, 2011. 